\title{
Managing Sustainable Development of Rural Areas Using Algorithms of Agricultural Specialization
}

\author{
Alexander Yu. Pavlov \\ Penza State Technological University \\ Email: crsk@mail.ru
}

\section{Doi:10.5901/mjss.2015.v6n3s5p147}

\begin{abstract}
The aim of this study is to develop a sustainability management system in rural areas through the use of the algorithm for determining agricultural specialization. Methods of determining prospective directions of development of agriculture is developed by the author based on cluster technology and tested in a study of rural areas of the Penza region, situated in the Central European part of Russia. The algorithm includes a number of stages: collection and processing of statistical information, the use of cluster analysis, the use of weighting factors characterize clusters and clustering objects, and the study of marketing, production facilities, climatic conditions. During the clustering of rural areas using k-means, the significance of certain cluster indices is determined (5-10\% error). If the factors are not significant, it indicates that the crop can be grown everywhere, or in a limited number of areas, which indicates their specialization. On this basis, the article provides recommendations for a change in direction for the agricultural specialization of Neverkinsk municipality. Thus, differentiation of rural areas, depending on the indicators of socio-economic subsystems and specialization of agricultural production allows to allocate specific 'points of growth' to each of them based on suitability to the different types of activities, and to develop targeted programs of the territory management on the basis of step analysis.
\end{abstract}

Keywords: sustainable development, rural areas, agricultural specialization, control algorithm

\section{Introduction}

Rural development is a key condition for the stability of the state, strengthening the country's food security. Thus, workers employed in agriculture, provides jobs for five to seven people in other sectors of the economy. With the adoption by the EU and Russian of a legislation, where one of the tasks of the state agrarian policy is the sustainable development of rural areas, increasing rural employment and their standard of living, and interest in the problems of rural areas at all levels becomes increased significantly (Gordeev, 2005).

The concept of 'sustainable development' was first introduced by the Brundtland report in 1987. Later, the requirement of environmental integration in all policies was presented in Maastricht Treaty of 1992 and reinforced in the Amsterdam Treaty in 1997. However, the discussion about what criteria should be taken into account in the development of strategic objectives and methodological tools for sustainable rural development is still ongoing (Young et al., 2005).

Relevance of research topic on rural areas is mainly defined by the following reasons:

- rural areas face problems that undermine national security;

- the countryside has often untapped economic potential, the development of which would improve the welfare of the population;

- there is an urgent need to overcome the differentiation of rural development and search for tools of reducing negative external influences.

These reasons are due to the fact that rural areas in most countries of Europe, as well as Russia are going through a systemic crisis, which is manifested in the deterioration of the demographic situation, high unemployment, the destruction of the existing framework of settlement. There is no doubt that in the past, the agricultural sector served as an engine for the growth of the rural economy and was the dominant source of income for rural residents. Rural and agricultural issues were considered as synonyms. It was believed that the objectives of agriculture and rural development are identical to each other. However, in recent years the situation has changed significantly. At the time, as full-time employment in agriculture is declining, the part-time and non-agricultural employment becomes a feature of the labor market in rural areas (Batova \& Rassadin, 2014).

The complexity and ambiguity of the reforms carried out in the rural areas have staticized the problem of theoretical justification of the municipal development strategy, the development of new methods of evaluation of 
agricultural and industrial potential of the territory, the state of its infrastructure and social sector development, which would meet the challenges of the time. The complexity is due to the required tools for considering the geographical location and climatic conditions, the demographic situation, the mentality of the population. Hence, the particular relevance and importance gains the use of ideas and conceptual framework of sustainable development in developing a strategy for overcoming crisis for competitive rural areas.

\section{Literature Review}

The definition of 'rural areas', adopted by the OECD (1994) and the European Comission (1997) reads as follows: it is the countryside, covering people, territories and other resources, and social landscape of small settlements outside the immediate sphere of economic activity of big city centers.

In statistics of the European Union the following systematics is used - the single framework of regional statistics (Nomenclature of Territorial Units for Statistics - NUTS), which is regarded as accounting administrative units classified according to several levels of subordination. Rural areas in Europe account for about $86 \%$ of the territory and about $75 \%$ of the municipalities belonging to the category LAU2 (Local Administrative Units), forming the core element of the statistical nomenclature of territorial units of regions (Jonard et al., 2009; United Nation, 2008). Table 1 shows the criteria used in different EU countries to assign the status of the territory of the countryside.

Table 1. The main criteria for attribution the territories to the rural areas in $\mathrm{OECD}$

\begin{tabular}{lc}
\hline Criteria to be applied & Countries \\
\hline Areas with a low population density and scattered population & Finland \\
\hline Areas with a population less than 2 thous. people & Greece, Spain \\
\hline Areas related to agriculture with a low population and structure density & Italy \\
\hline Areas outside settling with the population more than 200 people & Sweden \\
\hline
\end{tabular}

Source: based on OECD, 1999.

Thus, the interpretation of the term in official documents is focused on population density and geo-statistical units, giving the rural areas an administrative nature and ignoring the functional component, which reflects their socio-economic importance.

Therefore, in this study it is suggested to use the approach offered Bernard Kaiser (1990), which describes a rural area as sum of the following elements:

1. The low density of population and development, causing the spread of 'green landscape';

2. Use of space primarily for agricultural purposes;

3. Lifestyle of population, reflecting the affiliation to small settlements and closeness to nature;

4. Formation of the mentality of the people under the influence of peasant background.

Given the importance of the selected items, one can define the objectives of sustainable development of rural areas:

- Diversification of agricultural production (Hjalager, 1999);

- Multifunctionality of agriculture (Morgan et al., 2010);

- Raising the level of food security (Ayres and McCalla, 1996);

- Increasing employment and rural incomes (Shortall \& Shucksmith, 2001);

- Rational use of natural resources (Emerson \& Gillmor, 1999);

- The preservation of social and cultural traditions in rural areas (Kneafsey, 2001; Szlanyinka, 2009).

Achieving these goals requires the implementation of effective mechanisms for economic and social development, taking into account the characteristics of individual rural areas and high indicators of differentiation even within the same region.

\section{Methodology}

The solution of large and complex issues to achieve strategic objectives by linking them with the economic potential of the area by using a set of methods, techniques and tools is possible only on the basis of program-target approach. In order to identify integrated economic potential and promising directions of development of rural areas it is provided to use 
the author's algorithm, shown in Figure 1.

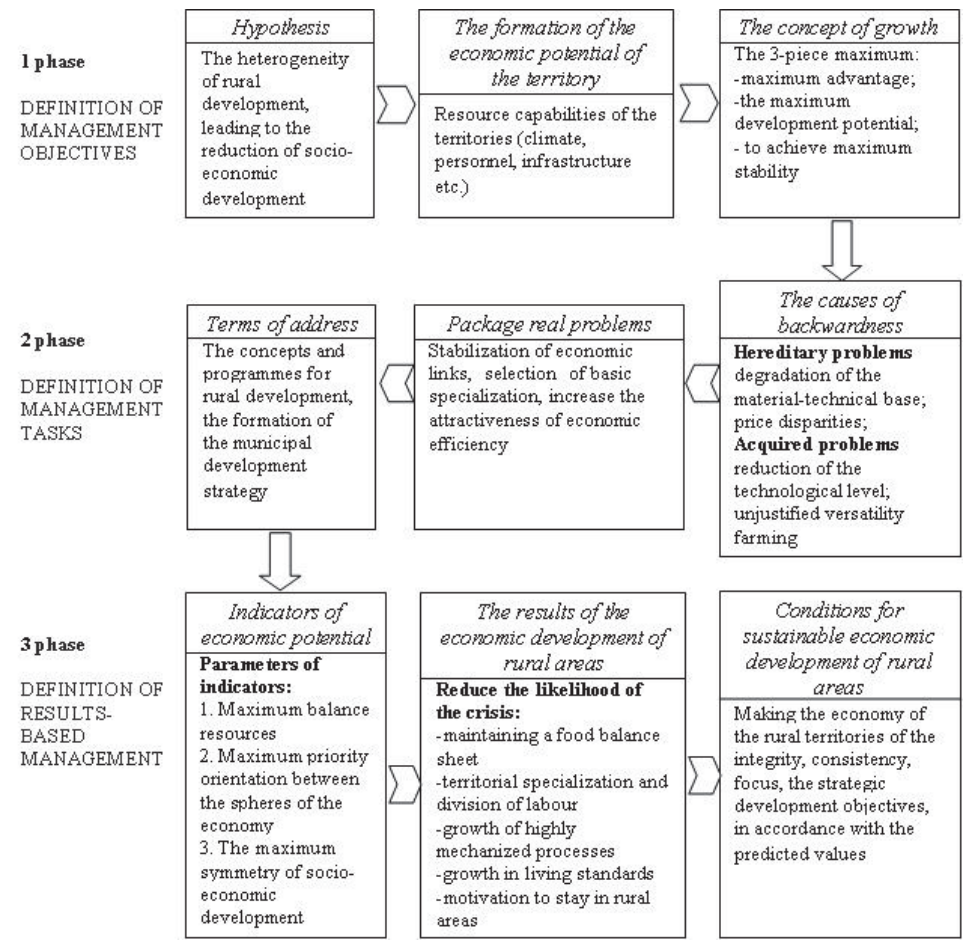

Figure 1. Management of development of rural areas through a step-by-step analysis

The main performance indicators of the level of rural area are the data of the following subsystems: a) the standard of living of rural people; b) the resource potential of the territory (human, natural, agricultural, industrial, tourism, engineering and infrastructure); c) provision of the territory by the social infrastructure (number of schools, hospitals, cultural and recreational facilities, etc.); d) budget and financial security.

According to the analysis of the above subsystems, the target direction for the formation of municipal programs related to the achievement of sustainable development of the territories and the degree of differentiation of socioeconomic status is defined.

The basis of groupings of rural areas is the level of specialization. It is the result of a territorial division of labor, due to the ability to produce certain types of products in an amount much greater than local needs, with a relatively low cost of labor. In essence, the ability to develop such industries whose products are competitive on international markets and predominantly focused on export. Therefore, it is important to discover the factors that can cause changes in areas of economic development and to identify new specializations of municipalities.

Since the agrarian specialization is the prevalence in most rural areas, it is appropriate to the use methods for determining the long-term perspective of agriculture, developed by the author in the study of rural areas of the Penza region, situated in the Central European part of Russia.

The author's method for determining the agricultural specialization in rural areas is developed on the basis of cluster technology and includes a number of stages: collection and processing of statistical information, the use of cluster analysis (hierarchical and non-hierarchical methods), the use of weighting factors that characterize clusters and clustering objects, the study of sales, production base, climatic conditions, etc. (Figure 2). 


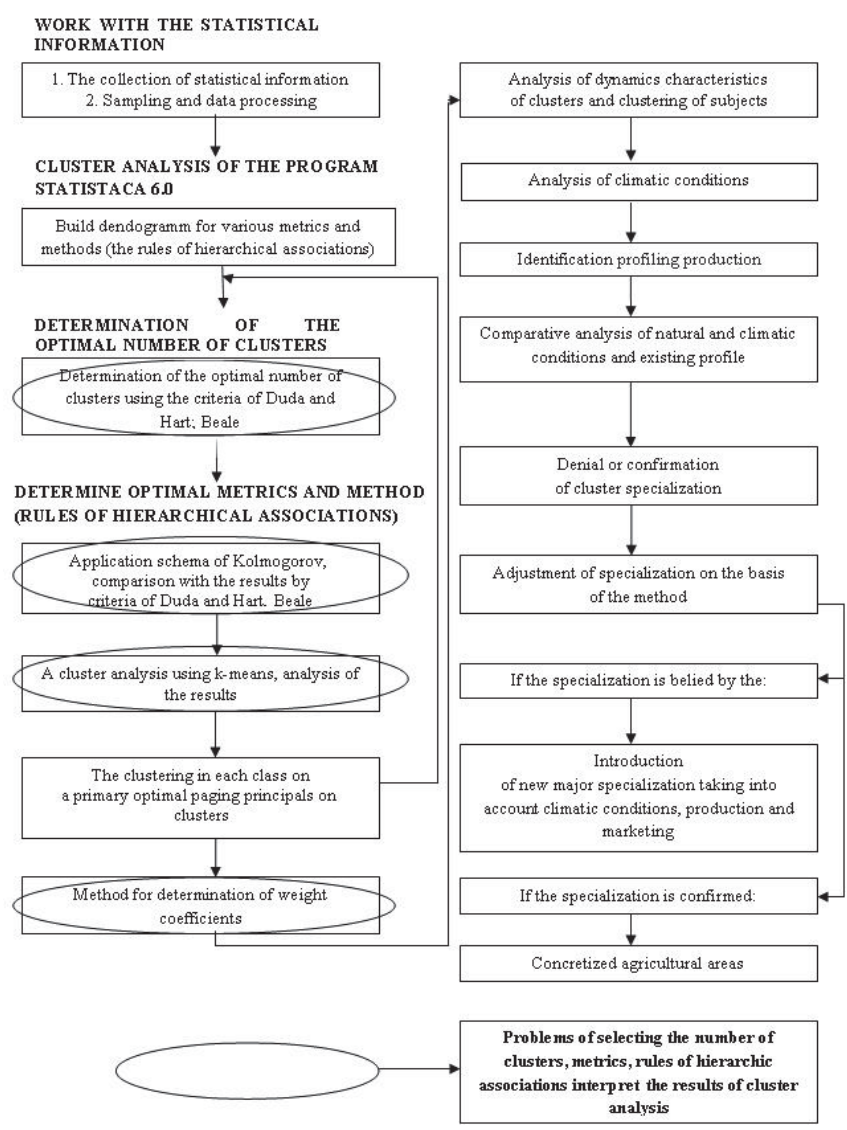

Figure 2. The algorithm for determining the agricultural specialization of rural territories

The main parameters that determine the agricultural specialization are the following: the yield in the context of crops, livestock figures (the number of pigs, cattle, etc.), indicators of production (milk production, the weight of cattle and poultry for slaughter, average daily gain cattle and pigs, the cost of production). These indicators were selected from the entire set of available statistical data on agriculture (Rosstat, 2012; OECD, 1996). In addition, the analysis does not include figures who have expressed strong relationship with other indicators (multicollinearity). A preliminary analysis was carried out using the MS Excel package.

The clustering has shown optimal metrics ('Euclidean distance'), thus it is possible to use the method of k-means (Khalafyan, 2007) and to check the quality of the result of the partition of municipalities into homogeneous groups. Within each cluster obtained, a secondary clustering is performed in order to determine the most similar objects.

There are five blocks of different characteristics of indicators allocated: 1 block - high ('best') indexes, 2 block higher than average, 3 block - average, 4 block - performance below average, 5 block - low ('worse') performance. Linguistic interpretation, for example, the group 'worst' performance: low crop yields (by species), low number of cattle, pigs, etc. Since all five blocks are equivalent, the total weighting coefficient (TWC) of poor performance will be $1 / 5$ of the 100 , i.e. $20 \%$. TWC of average performance is the average value of the common factors of the best and worst performance, so it is $60 \%$. Thus, the TWC of indicators starting with the first block will have the following ratios: $100 \%$, $80 \%, 60 \%, 40 \%$, and $20 \%$.

Depending on the purpose, the total weighting coefficient (or integral value) may be altered. With regard to the agro-industrial complex, the most interesting development is of the overall development index (ODI) produced based on the amount of integrated indicators of crop (IIC), livestock (IIL) and production (IIP).

Furthermore, during clustering of rural areas using the k-means, we can determine the parameters of clusters that differ significantly or insignificantly (5-10\% error). If the figure for agricultural parameter (e.g. cultivation, yield, etc.) is 
significant, it is possible to conclude for a strong difference in areas, i.e. in one area the specialization on the culture is possible, and in the other the cultivation shows lower rates and agricultural profile will be different. If the factors are not significant, it indicates that a culture can be grown everywhere, or in a limited number of areas (almost never), taking into account climatic conditions, production base, sales, the likelihood of yield reduction when abnormal weather is observed.

\section{Research Results}

Application of the proposed method was carried out in the study of the development of rural municipalities of the Penza region for the period 2011 - 2013 years. Figure 3 shows the distribution of municipal areas of the region by three territorial clusters.

The first cluster is characterized by high integral indicator of crop production, the indicators for production and animal husbandry is above average, total integral indicator of the development of agriculture is higher than the average for the population. The second cluster is close to the average performance and the total values. The third cluster is characterized by low aggregate indicator of the development of agriculture.

The analysis showed that in some years there is a shift of some municipalities from one type to another. Often holding a transport route, the creation of an industrial unit or animal systems can determine the change in the direction of area specialization. Therefore, the identification and correction of the existing agricultural specialization is an important issue of development effectiveness in rural areas.

Using the algorithm shown in figure 2, the main directions in agriculture of Neverkinsk municipal district that is located in the southeastern part of the Penza region is determined. As for 2011 - 2013, it retained its position in the third cluster, and the need for change is clearly seen.

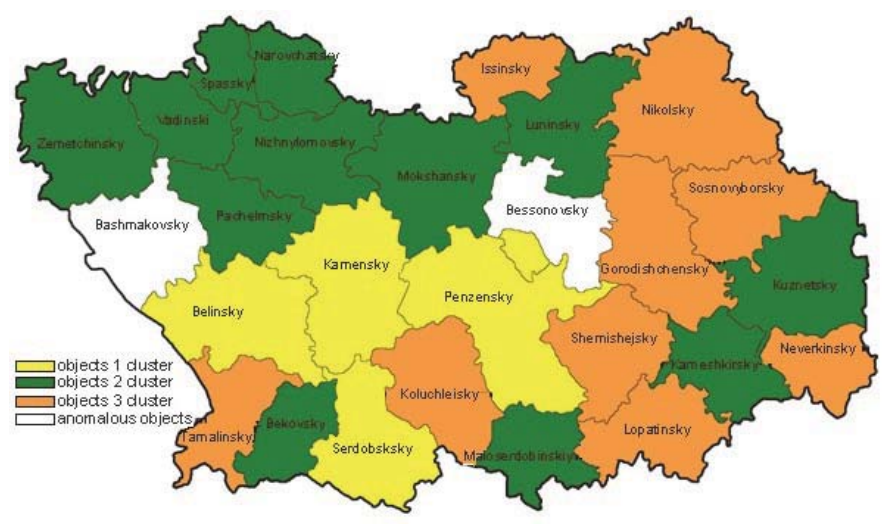

Figure 3. Differentiation of rural municipalities of the Penza region on indicators of agricultural development

Analysis of climatic conditions showed that the prevailing types of soils in the area of Neverkinsk district are leached black soil and dark gray forest; minor: ashed black soil, light gray forest. Soil fertility is $60 \%$, the degree of erosion of soil $-50 \%$, the sum of average daily temperatures of air - 2300 rainfall - $250 \mathrm{~mm}$, the climate is moderately moist.

Municipal target program "Development of agriculture of Neverkinsk municipal district" identified crop production of grain, sunflower and fodder as the major aspects of the industry. Sowing of grain and leguminous crops traditionally occupied $40 \%$ of arable land. The yield is about 16 t/ha. Comparing the performance with other grain-growing areas in the region, it can be said that the cultivation of cereals in the Neverkinsk district has a forage nature aimed at selflivestock provision. The development of commodity production of quality grains without attracting modern technology and selection achievements is rather difficult. In this regard, the increase in income from growing crops is possible only in conjunction with the development of meat and dairy cattle.

Production of sunflower oil seeds also cannot be considered as an optimal profiling direction. The security maturing and reaching agronomic phases of development (in 90\% of years) for the Penza region (Chirkov, 1969) is observed in the heat resource index (the sum of the temperatures above $\left.10^{\circ} \mathrm{C}\right)-2600^{\circ} \mathrm{C}\left(2400^{\circ} \mathrm{C}\right.$ in Neverkinsk district), that is, earlymaturing varieties of sunflower that give oil seed yielding up to $40 \%$ are grown. The average yield of sunflower in the district is $7-5$ t/ha. 
Based on the production base, formed in the district, it can be said that the established areas are forage production ('Neverkinsky feed mill') and processing of milk ('Neverkinsky creamery'), making dairy farming a priority.

Above all, due to the predominance of the population professing Islam (Tatars) - the religion that forbids using certain types of meat, perhaps the intensive development of sheep farming is favorable for the district, which is observed recently in the farms. The natural conditions of the district encourages engaging in herding, as $7 \%$ of the area of agricultural land are pastures (five thous. ha.).

Taking into account the climatic conditions, the results of the analysis of localization of cropping using k-means, as well as current production base and distribution system, the following recommendations are given: a) sheep breeding is a profiling trend in livestock, while preserving meat and dairy cattle breeding; b) in crop production - potato production, feed (including melon crops, annual and perennial grasses).

Thus, districts with a high potential for the development of specific areas of agriculture, often choose the path that brings lower efficiency. Improperly selected profile is drawn to the fact that farmers are faced with problems in manufacturing, sales, storage of products, resulting in low profitability. The amount of tax deducted in the budget is reduced, increasing the dependence of municipalities on the subsidies allocated from the regional and federal budgets.

Therefore, the basis for sustainable agricultural development should be based on targeted programs of agroeconomic development of municipal districts, based on the developed methodological approach of defining the agricultural specialization, which enables farmers to choose the effective, less risky and beneficial specialization.

\section{Conclusion}

Because of the complexity and dynamics of the phenomenon under study (the sustainable development of rural areas), the applied research methodology has to be versatile and multi-stage. A contemporary view of sustainability from the perspective of economics, sociology and ecology, supplemented by the paradigm of multifunctionality of agricultural production is the important base for the development of targeted programs for the sustainable development of rural areas. Smoothing the sharp differences and overcoming the crisis in the rural municipalities are not possible without state participation. It is helpful to use the proposed socio-economic indicators, especially for depressed areas, by applying the elaborated phased analysis and algorithm of defining the specialization. The need to support rural areas is due, primarily, to the fact that they not only ensure food security of the country, but also are a major source of work force of the cities, the repository of national traditions and customs.

\section{Acknowledgment}

Research carried out in the framework of the state task of the Ministry of Education and Science of Russian higher education institutions in terms of research on the topic "Interdisciplinary humanities and social studies in the context of innovative development and international relations".

\section{References}

Ayres, W. S., \& McCalla, A. F. (1996). Rural development, agriculture and food security. Financ. Dev., 33, 8-11.

Batova, V. N., \& Rassadin, V.V. (2014). Strategic management of enterprise labour potential as a tool for economic security. Middle East Journal of Scientific Research. J, 21 (2), 401-405.

Chirkov, Yu. I. (1969). Agrometeorological conditions and productivity of maize. Gidrometeoizdat.

Emerson, H. J., \& Gillmor, D. A. (1999). The rural environment protection scheme of the Republic of Ireland. Land Use Policy, 16, 235245.

European Commission (1997). Reform of the Structural Funds, COM (98)131def.-98/0090.19 March

Gordeev, A. B. (2005). The problem of food security and sustainable agricultural development in the world and Russia: Sustainable agriculture and rural areas of foreign experience and problems Russia. Moscow, Publishing scientific publications KMK.

Hjalager, A. (1999). Agriculture diversification into tourism: evidence of a European community development programme. Tour. Manage, 17, 103-111.

Jonard, F., Lambotte, M., Ramos, F., Terres, J.M., \& Bamps, C. (2009). Delimitations of Rural Areas in Europe Using Criteria of Population Density, Remoteness and Land Cover. JRC Scientific Report.

Kaiser, B. (1990). La renaissance rurale. Paris: Armand Colin.

Khalafyan, A. A. (2007). Statistica 6. Statistical analysis: Textbook . Moscow: Bean -Press.

Kneafsey, M. (2001). Rural economy: tourism and social relations. Ann. Tour. Res., 28, 762-783.

Morgan, S. L., Marsden, T., \& Morley, A. (2010). Agricultural miltifunctionality and farmers entrepreneurial skills: a study of Tuscan and Welsh farmers. J. Rural. Srud., 26, 116-129. 
OECD (1994). Creating Rural Indicators for Shaping Territorial Policies. Paris: OECD.

OECD (1996). Territorial Indicators of Employment - Focusing on Rural Development. Paris: OECD.

OECD (1999). Trends in Rural Policy Making and Institutional Frameworks, Paris: OECD.

Rosstat. (2012). Municipalities database performance. Federal State Statistics Service. [Online] Available: http://www.gks.ru/dbscripts/ munst/munst56/DBInet.cgi (February 25, 2015).

Shortall, S., \& Shucksmith, M. (2001). Rural development in practice: issues arising in Scotland and Northern Ireland. Community Dev. J., 36, 122-133.

Szlanyinka, E. (2009). The role of cultural values in rural development. In: V. T. de Noronha, P. Nijkamp, \& J. Rastoin (Eds.) Traditional Food Production and Rural Sustainable Development: a European Challenge. Ashgate Publishing. Surrey.

United Nation. (2008). Urban and Rural Areas 2007. United Nation Publication Biodiversity and Conservation, 14, $1641-1661$.

Young, J., Watt, A., Nowick, P., Alard. D., Clitherow, J., Henle, K., Johnson, R., Laczko, E., Mccracken, D., Matouch, S., Niemela, J., \& Richards, C. (2005). Towards sustainable land use: identifying and managing the conflicts between human activities and biodiversity conservation in Europe. Biodivers. Conserv., 14. 
